\title{
A CASE OF RUPTURE OF THE HEPATIC DUCT IN A NEWBORN INFANT
}

\author{
BY \\ JOAN P. WRIGHT and HELEN E. WORSLEY \\ From the Duchess of York Hospital for Babies, Manchester
}

(RECEIVED FOR PUBLICATION NOVEMBER 19, 1958)

A successfully treated case of a perforation in the biliary system of a newborn infant is presented. Cases have been reported in which bile peritonitis has occurred in association with rupture of a congenital cyst of the common bile duct (Byrne and Bottomley, 1953). Only six cases of perforation in the biliary tract have been found in which symptoms began in the neonatal period and in which the biliary system at laparotomy appeared otherwise normal (Caulfield, 1936; Mason, Sidbury and Guiang, 1954; Pettersson, 1955).

\section{Case History}

E.A.W. was the first child of healthy parents and was born in a maternity home on April 14, 1958, weighing $7 \mathrm{lb} .14 \mathrm{oz}$. Delivery was normal and she was perfectly well until the fifth day. It was then reported that the stools were pale and that she was reluctant to take feeds. On the ninth day she vomited after every feed, was pale and unwell and was transferred to the Duchess of York Hospital under the care of Dr. S. K. Guthrie. On examination the child was apyrexial and was in good general condition. She was very slightly icteric and there was minimal abdominal distension with general tenderness. No signs of free fluid in the abdominal cavity were elicited. The stools were pale and the urine a normal colour.

Investigations. Haemoglobin was $15 \cdot 7$ g., E.S.R. was $3 \mathrm{~mm}$. in one hour, and W.B.C. was 3,000 (polymorphs $45 \%$, eosinophils $1 \%$, plasma cells $1 \%$, lymphocytes $51 \%$, monocytes 2\%). Serum bilirubin (micro.) $2 \cdot 4 \mathrm{mg} . \%$. There was a trace of bile pigments in the urine, but no urobilinogen. A straight radiograph of the abdomen was normal.

Progress Report. After admission the child continued to pass clay-coloured stools and to vomit after every feed. By the following day her general condition had deteriorated; she had become slightly dehydrated and there was increasing abdominal distension. At this stage she was noticed to have a yellow stain extending from the right hypochondrium to the right iliac fossa. Within a few hours this staining had spread to the hypogastrium and the left iliac fossa. A surgical opinion was sought and the child was seen on the day after admission by Mr. N. F. Kirkman, who decided to carry out an immediate laparatomy.

Operative Details. A transverse epigastric incision was made. There was bile staining of all deep tissues and a moderate amount of free bile in the peritoneal cavity. A small irregular hole about $\frac{1}{2} \mathrm{~cm}$. in length was found in the hepatic duct near the hilum of the liver. There was a small area of necrosis surrounding the perforation and a little inspissated bile in the lumen of the duct. The gall-bladder was empty. A probe was passed without difficulty into the lumen of the duct and apart from the perforation the biliary tract appeared normal. The bile duct was drained externally by a rubber catheter with side holes which was passed through the perforation and along the duct towards the duodenum. Separate drains were placed in the peritoneal cavity through stab wounds to drain the right and left paracolic gutters, and the abdominal wall was closed.

Post-operative Progress. An intravenous infusion had been started pre-operatively and was continued for 48 hours. She was given initially $250 \mathrm{ml}$. N/5 saline in $4.3 \%$ dextrose followed by $5 \%$ dextrose in water. On the second post-operative day she was given $100 \mathrm{ml}$. of whole blood. Throughout this period small feeds were given and were retained and the child's general condition was good. On the second day she passed a small stool containing bile. On the eighth day a choledochogram was performed using $1 \mathrm{ml}$. of lipiodol; this showed normal hepatic and common bile ducts, the dye passing freely into the duodenum. The catheter draining the bile duct was removed and the child made an uneventful recovery. When seen at 3 months of age she was in all respects a normal child.

\section{Comment}

The cause of the rupture was not obvious at operation and the following aetiological factors have been considered.

Infection. Although the child had a mild infection of the umbilicus there was no evidence of infection in the hilum of the liver and the possibility 
of necrosis of the duct following infection is therefore discounted.

Birth Trauma. There are many cases in which rupture of the liver was caused by birth trauma (Genell, 1930; Potter, 1940; Arden, 1946 and 1951). In none of these cases was there any damage to the biliary tract. It is difficult to postulate a strain to the biliary tract leaving the liver intact.

Congenital Abnormality. In the case reported here a plug of inspissated bile was found in the duct distal to the site of perforation. This caused obstruction of the duct, pale stools having been noticed from the fifth day. On the ninth day the patient started to vomit after every feed and was obviously not as well. We suggest that the perforation occurred at this stage, giving rise to the later signs of abdominal distension and bile staining of the skin. Byrne and Bottomley (1953) reported a case of congenital cyst at the junction of the cystic and hepatic ducts, this being the site of rupture. Pettersson (1955) reported four cases, in three of which he found no obstruction in the ducts, but in one of which he found a plug of mucus at the ampulla of Vater. These four cases had all ruptured at the junction of the cystic and hepatic ducts, and, quoting Byrne and Bottomley, Pettersson suggested that this site may be subject from an embryological point of view to structural weakness or diverticulae. He suggested that a stenosis of the duct or a plug in the duct or ampulla of Vater would be a contributory factor. The case reported here had many similarities to those described by Pettersson. The initial symptoms of vomiting and pale stools, and the later signs of peritonitis being present in all cases. At operation the appearance of the perforation was similar, but in this case occurred in the hepatic duct just above its junction with the cystic duct. We suggest that a congenital weakness was present at this unusual site and that the theory of Pettersson as to the causation of the rupture is applicable to this case.

\section{Summary}

A successfully treated case of rupture of the hepatic duct with symptoms presenting at the fifth day of life is reported. Possible causes are considered with special reference to the theory postulated by Pettersson (1955).

We wish to thank Dr. S. K. Guthrie and Mr. N. F. Kirkman for permission to publish this case and for their helpful advice.

REFERENCES

Arden, F. (1946). Med. J. Aust., 1, 187.

Byrne, J. J. and Bottomley, G. T. (1953). A.M.A. Amer. J. Dis. Child., 85, 694.

Caulfield, E. (1936). Ibid., 52, 1348.

Genell, S. (1930). Acta obstet. gynec. scand., 9, 180.

Mason, L. B., Sidbury, J. B. and Guiang, S. (1954). Ann. Surg., 140, 234.

Pettersson, G. (1955). Acta chir. scand., 110, 192. 